\title{
On the Ethical Feasibility of "National Fertility" Strategy Under the Crisis of Fewer Children
}

\author{
Jingtao Jiang \\ Research Centre of Medical Humanities, Zunyi Medical University, Zunyi, China
}

Email address:

452948546@qq.com

To cite this article:

Jingtao Jiang. On the Ethical Feasibility of "National Fertility" Strategy Under the Crisis of Fewer Children. Humanities and Social Sciences. Vol. 9, No. 5, 2021, pp. 181-186. doi: 10.11648/j.hss.20210905.16

Received: September 9, 2021; Accepted: September 24, 2021; Published: September 29, 2021

\begin{abstract}
Background: The crisis of fewer children is a series of negative impacts brought by the decline of natural fertility rate. The trap of low fertility intention brought about by social development leads to the ineffectiveness of all measures to increase the willingness of young men and women to have children. The artificial fertility rate can be greatly increased by natural science technologies of sperm bank, egg bank, artificial insemination and artificial uterus in the production stage, as well as the management technologies of relevant institutions in the rearing stage. This kind of national fertility strategy is technically feasible, but ethically controversial. Objective: This paper tries to sort out the possible ethical criticism of the natural technology adopted by the national fertility strategy in the production stage and the management measures adopted in the rearing stage, and classifies them into several core categories. Then the specific ethical criticism clauses under the above core categories are analyzed one by one to see whether they are valid or can be avoided. Conclusion: Most of the ethical criticisms of the national fertility strategy are themselves untenable. Even if some ethical criticisms are valid, they can be avoided by restricting and regulating the application of natural technologies and management measures. At the same time, the national fertility strategy is of great significance to the survival of the nation, so it is worth advocating.
\end{abstract}

Keywords: Crisis of Fewer Children, National Fertility Strategy, Technical Feasibility, Ethical Feasibility

\section{Introduction}

Japan's population decline in 2020 is estimated at 420,000, surpassing the record high set in 2019 and marking the 11th consecutive year of decline. The number of registered Koreans in 2020 dropped by 20,000 from the previous year for the first time to decline in history. The release of China's seventh national census also shows that the number of newborn babies has decreased year by year. Fewer children has become a common phenomenon in East Asia, and the same trend even appears in the world. The global fertility rate has been in steady decline since the 1960s. [1] The reduction of children has brought great negative impact to all countries, and Japan even called it a national disaster. Many countries have introduced a lot of policies to deal with the crisis of fewer children, but the effect is not obvious. [2]

In view of this problem, this paper first discusses "the fertility trap of development" behind the crisis of fewer children. It is argued that all measures to improve the fertility willingness of young men and women are invalid, so a national fertility strategy is needed to deal with it. Then this paper demonstrates the technical and ethical feasibility of this kind of national fertility strategy. Finally, this paper concludes that the national fertility strategy is technically and ethically feasible, and is worth advocating in view of its great significance.

\section{The Reasons and Countermeasures of Fewer Children Crisis}

The causes of the fewer children crisis can be divided into two categories: one is the decrease of the internal willingness of young men and women to give birth and raise children; the other is the lack of external ability of them to give birth and raise children.

The latter is mainly reflected in the following aspects:(1) Young men and women are under great pressure of working and living, and lack enough time and energy; (2) The economic cost of production and upbringing is high and 
unaffordable; (3) The labor cost of production and upbringing is high and unaffordable. In most countries, the response to the crisis of fewer children also tends to focus on these external causes. Taking Japan as an example, its countermeasures to the crisis of fewer children mainly include: (1) Reduce work pressure, so that male and female employees will have more leisure time to devote to family life; (2) Provide economic assistance to reduce the economic burden of raising children; (3) Improve infant care services to reduce the labor burden of raising children. [3] It can be seen that the existing strategies for coping with the fewer children crisis, represented by Japan, are mainly aimed at the external production and nurturing capacity of young men and women, but lack of targeted measures to improve their internal willingness. In fact, internal will is the most important factor in deciding whether or not to have children.

As for the internal intention to procreate, any attempt to increase this intention of young men and women will be ineffective because of the trap of low fertility intention brought about by social development. The trap of low fertility intention brought about by social development refers to the fact that social development inevitably leads to the improvement of population quality and the decline of fertility intention. To be specific, the development of productive forces makes the corresponding production tools and production objects become more complex and precise, which inevitably requires a higher quality of the working population. The requirement of higher labor quality forces young men and women to spend a lot of time and energy on systematic learning and training, which can only be achieved through their own internal efforts, and external support measures are ineffective. Only when their own quality has reached a certain height to meet the requirements of work can young men and women have extra time and energy to consider the question of having children. A person's time and energy are limited, so the more society develops, the higher the requirements of population quality, young men and women will inevitably have less intention to bear children. The willingness to procreate will inevitably decrease, so that all measures around increasing the willingness to procreate will be ineffective. The increase in population cannot depend on the willingness of young men and women, so it has to be increased by other means, by means of unnatural production and rearing. This requires us to use assisted reproductive technology to replace traditional young men and women for baby production, and at the same time to use social institutions to replace traditional young parents for child rearing. The production and rearing here must be treated with great care, and only the government representing the entire nation has such qualifications and capabilities. Therefore, this paper propose a national fertility strategy.

The national fertility strategy means that the government, on behalf of the entire nation, gives birth and raises children artificially through technology LABS and management organizations, rather than relying on young parents. This kind of national fertility strategy mainly includes two steps of production and rearing. The production step involves obtaining the fertilized egg through artificial insemination and growing it to maturity in an artificial uterus until birth. The rearing step is mainly through state-owned welfare homes, schools and other social institutions to foster the physical, psychological and social quality of minors until they become adults.

\section{Technical Feasibility of National Fertility Strategy}

The national fertility strategy is not mature now in technology include natural science technology and management technologies, but it already has a strong foundation. Because there is no insurmountable gap, as long as enough money is invested in the existing foundation, the operation of the system can be found quickly.

In the stage of production, it mainly involves three natural science technologies: sperm and egg bank, artificial insemination and artificial uterus. Human sperm banks have become so mature that many countries around the world have established and operated male sperm banks for a long time. [4] Human egg banks are technically available, but they are far from ideal in terms of egg harvesting damage, storage life and thawed cell viability, and there are only a few operating in the world. [5] Artificial insemination technology is also very mature, now many hospitals have test-tube baby project, using artificial insemination technology. [6] Artificial womb refers to a system that mimics a woman's womb environment and supports fetal development by providing appropriate nutrients and oxygen. Currently, artificial wombs can only partially replicate the functions of the mother's uterus to achieve basic life support, but there is still a long way to go to fully replicate the function of the human uterus. The promise of artificial wombs has attracted research groups from around the world. In October 2019, the European Union's Horizon 2020 programme awarded 2.9 million euros to Dutch scientists to develop artificial wombs, with the aim of completing the trials and putting them into clinical use by 2025 . It is believed that with people's attention and investment of more resources, the real mature artificial womb technology will be realized soon. [7] In general, the technical feasibility of national fertility strategy in production stage is very high. Even if there are some disputes, most of them can be resolved through further negotiation and agreement.

In the stage of rearing, it mainly includes the management technologies of cultivating the physical, psychological and social qualities of children. Physiological quality cultivation is mainly to meet the needs of minors in food, safety, warmth, sleep, health and other aspects. The cultivation of psychological quality is mainly to satisfy the emotion, attitude, cognition, knowledge and other needs of minors. Social quality cultivation is mainly to meet the needs of minors in kinship relationship, organizational affiliation, code of conduct, etc.. These are already existing functions of welfare homes, schools, and public welfare organizations, but they are obviously not enough for the national fertility policy. The first is the lack of a systematic integration. Secondly, there is a big gap in the details of the source of funds, staff quality, 
management level, care model, social interaction and other aspects. But this is not an insurmountable obstacle, but one that can be quickly resolved with sufficient time and effort. In general, the implementation of national fertility strategy in the rearing stage is also highly feasible. Even if there are some disputes, most of them can be resolved through further negotiation and agreement.

\section{Some Possible Ethical Criticisms of National Fertility Strategy}

The technical feasibility of national fertility strategy is not a big problem. There are no insurmountable obstacles and bottlenecks in the application of various natural science technologies and management technologies, either in the stage of production or in the stage of rearing. However, there may be many doubts about the ethical feasibility of the national fertility policy. Since the national fertility policy has not been explicitly proposed and discussed by other scholars, it is only some possible doubts here. These doubts should be carried out from two aspects, on the one hand, the application of natural technology in the production stage, on the other hand, the management technology measures in the rearing stage.

\subsection{Stage of Production}

Ethical criticism at the stage of production should mainly be directed at the three natural technologies of egg bank, artificial insemination and artificial uterus.

The ethical criticism of egg bank may be as follows: (1) Safety. Egg harvesting can cause unavoidable harm to young women, while the quality of frozen eggs may also negatively affect the health of future generations. (2) Consanguineous marriage. Anonymous donation can easily lead to sperm or eggs of the same donor being used many times, and their offspring may be inbred without knowing the truth. (3) Psychological alienation. Indirectly origins in the sperm bank rather than directly origins in the human body may have negative psychological effects on informed offspring, who perceive themselves as different from their peers. (4) Privacy protection. Whether future generations should know the truth about their biological parents is debatable. (5) Donor screening. There may be discrimination in donor selection, such as celebrity influence. (6) Commercialization. Commercial operation may impact the traditional social and cultural status of sperm and eggs. (7) Separation of sex and reproduction. The separation of sex and reproduction produces diverse sexual cultures that challenge traditional notions. [8]

Most of the ethical criticisms of artificial insemination are the same as those of egg banks, such as consanguineous marriage, psychological alienation, donor selection, separation of sex and reproduction, etc. Some are different such as: (1) Survival of the fittest. In the natural reproductive process of young men and women, differences in physical quality lead to differences in reproductive ability, while artificial insemination enables men and women with poor physical fitness to reproduce in large numbers. (2) Embryo status. Artificial insemination creates extra embryos, whether they are lives and what should be done with them is controversial. [9]

Most of the ethical criticisms of artificial uterus are the same as those of egg banks and artificial insemination. such as safety, psychological alienation, separation of sex and reproduction, embryo status, etc. Some are different such as: (1) Interaction during pregnancy. Babies born in artificial wombs lack a sense of their mother's emotions, sounds and movements, and their physical and mental health can be adversely affected. (2) Status of women. The traditional role of women as mothers will be challenged, and the corresponding social support system will also change greatly. [10]

To sum up, the ethical criticism of sperm bank, artificial insemination and artificial uterus can be summarized into three aspects: physiological, psychological and social. The ethical criticism of physiology aspect is mainly about safety, consanguineous marriage and survival of the fittest. The ethical criticism of psychology aspect is mainly about psychological alienation, privacy protection, interaction during pregnancy. The ethical criticism of social aspect is mainly about donor screening, commercialization, separation of sex and reproduction, embryo status and women status.

\subsection{Stage of Rearing}

Ethical criticism at the stage of rearing should mainly be directed at the three management technologies of physiological, psychological and social quality cultivation.

The main ethical criticism of physiological quality cultivation may be as follows: (1) Financial guarantee. It is doubtful whether the national government's financial support is timely and sufficient, and whether there is corruption in the implementation process. Biological parents give priority to feeding their children even if they are hungry, but it is hard for the employees of the national fertility system to give priority to the interests of children because they only take care of children as a job. (2) Changes in the political situation. There are at least 18 years between infancy and adulthood, during which different political, economic and cultural forces are likely to interfere with the normal implementation of national fertility policies out of short-sightedness, prejudice and self-interest. (3) Lack of tenderness and consideration. The management measures may be scientific enough, but after all, they are only some rigid macro norms, and it is difficult to comprehensively consider the changeable details of children's needs like biological parents.

The main ethical criticism of psychological quality cultivation may be as follows: (1) Personality development. Most children in the national fertility system are subject to standardized management measures, lacking independent space, free exploration and different choices, and their personalized appeal is easy to be ignored. (2) Domestic affection. Children in the national fertility system lack the psychological support that normal children can get from their biological parents, such as feelings of intimacy, security, trust, 
dependence and belonging. (3) Instrumentalism. Children in the national fertility system are merely treated as a potential Labour force, while children in normal families are placed infinite hopes by their parents. These two different treatments can have a big impact on the mindset of the children involved.

The main ethical criticism of social quality cultivation may be as follows: (1) Social adaptation. The management of national fertility system is relatively closed and it is difficult to ensure adequate training of interpersonal communication and social experience. (2) Brainwashing and utilizing. Children in the national fertility system are often strongly controlled and influenced by government authorities, and are easy to lose their critical consciousness of society. Children from normal families are only affected by their family background and have independent thinking and choices on social issues. (3) Competition of family background. Children in the national fertility system and those from normal families will inevitably compete with each other when they grow up and enter the society. Is the starting point of this competition fair is a big problem.

\section{Ethical Feasibility of National Fertility Strategy}

National fertility strategy is faced with many ethical questions in both the production stage and the rearing stage. However, most of these doubts have their own problems, or can be resolved through negotiation and agreement, there is no insurmountable ethical defects. Let's go through them one by one.

\subsection{Stage of Production}

The ethical criticism of physiology aspect is mainly about safety, consanguineous marriage and survival of the fittest. (1) Safety. It is first a matter of degree of technology maturity and then a process of weighing the pros and cons. As with new drug development, it must first go through rigorous phase IV clinical trials and then calculate the size of the side effects. [11] (2) Consanguineous marriage. This can be avoided through real-name registration. That means donors must register with their real names, the number of times their sperm and eggs can be used must be strictly limited, and their children should form a blood family. Children have the right to know about their biological parents when they become adults, but there should be no compulsory responsibility or binding relationship between them. (3) Survival of the fittest. Firstly, there is a screening process for genetic defects in artificial insemination, which is similar to the selection of the fittest. Secondly, the weak also have their basic right to survival, the survival of the fittest principle can not be applied to people. [12]

The ethical criticism of psychology aspect may be mainly about psychological alienation, privacy protection, interaction during pregnancy. (1) Alienation psychology. Both children born under the national fertility strategy and children born by their parents are developed from fertilized eggs, and the two are essentially the same. The differences between them are mainly artificial insemination and natural conception, and artificial uterus and maternal uterus. But these differences are only the difference between the external environment of the sperm and the eggs, one in a test tube and the other in the human body. It doesn't affect whether we can be a real human being. Just like test-tube babies and premature babies in incubators, they are not considered too strange to accept. [13] (2) Privacy protection. Minors in the national fertility system should not be given information about their biological parents to avoid being adversely affected. But when they become adults they should have a basic right to know about their biological parents. At the same time, because there is no compulsory responsibility and restraint between parents and children, it will not have a great negative impact on the further development of adult children. (3) Interaction during pregnancy. This can be made up through various means of fetal education. [14]

The ethical criticism of social aspect may be mainly about donor screening, commercialization, separation of sex and reproduction, embryo status and women status. (1) Donor screening. Discrimination is unequal treatment, but there is no such thing as discrimination if screening is carried out on the basis that everyone is equal before health standards. (2) Commercialization. There is no commercialization of the national fertility strategy because it is a public project that is carried out by the government and is responsible to the whole nation. (3) Separation of sex and reproduction. The widespread use of contraception is itself a classic manifestation of the separation of sex and reproduction, so it is not that separation that people concerns, but the status of sex and reproduction after separation. Sex became more of a way to get pleasure and reproduction more of a way to reproduce. For reproduction in particular, people can choose to give birth, not to give birth, or donate their sex cells to the state for use. Reproduction has changed from a passive instinct to an active choice, which is more conducive to human freedom and liberation. (4) Status of embryos. Different cultural backgrounds have different conventions on the status of embryos, and there is no absolute universal law. So people have to follow the most widely accepted one that exists, which is the 14-day rule for human embryo research [15]. (5) Status of women. Under the national fertility policy, men and women have become sperm and egg donors, making their status more equal.

\subsection{Stage of Rearing}

The ethical criticism on the cultivation of physiological quality may be mainly about financial guarantee, changes in the political situation and lack of tenderness and consideration. (1) Financial guarantee. The national fertility strategy must set a threshold for entry, and only countries that meet certain criteria such as political stability, economic vitality and national recognition can implement national fertility policy. (2) Changes in the political situation. The national fertility system must have certain independence and sufficient autonomy in education, management and revenue, so as to be responsible for the long-term interests of the whole nation without being 
influenced by the local authorities. (3) Lack of tenderness and consideration. First of all, not all biological parents are gentle enough. Secondly, the humanistic qualities of practitioners need to be strictly regulated and examined. Finally, practice standards must be detailed enough and their implementation needs to be fully monitored.

The ethical criticism on the cultivation of psychological quality may be mainly about personality development, lack of domestic affection and instrumentalism. (1) Personality development. Personality is a variety of branches based on a common backbone of human nature. Children can be encouraged to explore their own inner tendencies and develop a diverse personality if they are given enough options on the basis of conventional management measures. (2) Domestic affection. Firstly, if the child does not know, there is no difference between the affection provided by adoptive and biological parents. So as long as the national fertility system staff are dedicated enough, they can provide the same amount and quality of affection. Secondly, as mentioned above, the national fertility strategy encourages blood brothers and sisters to form a small family, which is also an important source of kinship. (3) Instrumentalism. The national fertility strategy is responsible for the whole nation and does everything we can to train the next generation to replace the older generation that will eventually pass away, so there is no question of instrumentalization.

The ethical criticism on the cultivation of social quality may be mainly about social adaptation, brainwashing and utilizing, and competition of family background. (1) Social adaptation. It is primarily a question of educational methods. As long as adequate social interaction and social practice are provided, the social adaptability of minors can be better cultivated. (2) Brainwashing and utilizing. As this paper have said before, the national fertility project must be an independent operation system independent of local conditions. The national fertility system cultivates the basic quality and ability of general education for children, and only after they are physically and psychologically mature can they discuss and study ideology and politics. (3) Competition of family background. There are three possible situations in the competitiveness of children from the national fertility system and those from normal families. If the two are equal, everyone is happy. If the former is weak than the latter, more humanitarian care should be given to the children from the national fertility system. If the former is stronger than the latter, then more humanitarian care for naturally conceived children is needed in turn. As is the case with today's widely accepted preferential treatment for ethnic minorities, this does not raise much ethical controversy.

\section{Conclusion and Further Extended Discussion}

As can be seen from the above discussion, the national birth policy is technically feasible, and it is also ethically feasible through the formulation of strict norms. At the same time, the national fertility strategy has strong realistic significance, so it is worth advocating.

The significance of national fertility strategy is as follows: (1) Ensure racial continuity and promote social prosperity. The national fertility policy ensures the population of a nation and provides enough high-quality population to promote the development and prosperity of the society. (2) Liberate labor force and enhance individual value. By freeing young men and women from the burden of childbirth and upbringing, the national fertility policy can help them better realize their personal value by promoting their study and work. (3) Scientific parenting, improve the quality of population. By adopting more scientific and rational rearing measures, the national fertility policy can raise the next generation with higher quality. Some instances of child neglect and abuse by irresponsible parents would also disappear [16]. (4) Create a paradise for children to promote their comprehensive and free development. The national fertility strategy will put the minors in a perfect growth environment, without the pressure of survival and persecution of external forces, only potential and quality training. This will enable them to develop in a more comprehensive and free way and to prepare for the social competition in the future.

\section{References}

[1] Morgan S P. Is low fertility a twenty-first-century demographic crisis? [J]. Demography, 2003, 40 (4): 589-603.

[2] Sleebos J. Low fertility rates in OECD countries: facts and policy responses [J]. 2003.

[3] Holthus B G. Child Care and Work-life Balance in low-fertility Japan [M] //Imploding Populations in Japan and Germany. Brill, 2011: 203-228.

[4] Rothman C. Clinical aspects of sperm bank [J]. The Journal of urology, 1978, 119 (4): 511-513.

[5] Akin J W, Bell K A, Thomas D, et al. Initial experience with a donor egg bank [J]. Fertility and sterility, 2007, 88 (2): 497. e1-497. e4.

[6] Morrell J M. Artificial insemination: current and future trends [J]. Artificial insemination in farm animals, 2011, 1: 1-14.

[7] Romanis E C. Artificial womb technology and the frontiers of human reproduction: conceptual differences and potential implications [J]. Journal of Medical Ethics, 2018, 44 (11): 751-755.

[8] Bhatia R, Campo-Engelstein L. The biomedicalization of social egg freezing: A comparative analysis of European and American professional ethics opinions and US news and popular media [J]. Science, Technology, \& Human Values, 2018, 43 (5): 864-887.

[9] Liao J, Dessein B, Pennings G. The ethical debate on donor insemination in China [J]. Reproductive biomedicine online, 2010, 20 (7): 895-902.

[10] Reiber D T. The morality of artificial womb technology [J]. The National Catholic Bioethics Quarterly, 2010, 10 (3): 515-527. 
[11] Singh N, Madkaikar N J, Gokhale P M, et al. New drugs and clinical trials rules 2019: changes in responsibilities of the ethics Committee [J]. Perspectives in clinical research, 2020, 11 (1): 37

[12] Paul D B. Darwin, social Darwinism and eugenics [J]. The Cambridge Companion to Darwin, 2003, 214 (10.1017).

[13] Bakewell-Sachs S, Gennaro S. Parenting the post-NICU premature infant $[\mathrm{J}]$. MCN: The American Journal of Maternal/Child Nursing, 2004, 29 (6): 398-403.
[14] Whitwell G E. The importance of prenatal sound and music [J]. Journal of Prenatal and Perinatal Psychology and Health, 1999, 13: 255-262.

[15] Pera M F. Human embryo research and the 14-day rule [J]. Development, 2017, 144 (11): 1923-1925.

[16] Radford L, Corral S, Bradley C, et al. Child abuse and neglect in the UK today [J]. 2011. 